\title{
Coeficiente de flambagem local para seção completa de um perfil $U$ enrijecido de chapa fina com mesa superior inclinada
}

\author{
Local buckling coefficient for thin-walled lipped channel section with top flange inclined \\ Coeficiente de pandeo local para la sección completa de un perfil en $U$ reforzado de placa delgada
}

con mesa superior inclinada

Recebido: 05/09/2021 | Revisado: 11/09/2021 | Aceito: 12/09/2021 | Publicado: 14/09/2021

\author{
Lucas Roquete \\ ORCID: https://orcid.org/0000-0002-7937-822X \\ Universidade Federal de São João Del-Rei, Brasil \\ E-mail: lucasroquete@ufsj.edu.br \\ Matheus Miranda de Oliveira \\ ORCID: https://orcid.org/0000-0002-4098-6383 \\ Universidade Federal de Ouro Preto, Brasil \\ E-mail: matheusmoliveira4@gmail.com \\ Fábio Nogueira da Silva Costa \\ ORCID: https://orcid.org/0000-0002-9251-1400 \\ Universidade Federal de São João Del-Rei, Brasil \\ E-mail: fabioncosta@gmail.com \\ Larissa Vieira Marinho \\ ORCID: https://orcid.org/0000-0001-5500-6547 \\ Universidade Federal de São João Del-Rei, Brasil \\ E-mail: larissavmarinho@hotmail.com \\ Arlene Maria Cunha Sarmanho \\ ORCID: https://orcid.org/0000-0001-6900-8551 \\ Universidade Federal de Ouro Preto, Brasil \\ E-mail: arlene.sarmanho@gmail.com
}

\begin{abstract}
Resumo
Este trabalho apresenta um estudo de perfis formados a frio não padronizados por norma, com tipologia $\mathrm{U}$ enrijecido (Ue) e mesa superior inclinada em $30^{\circ}$. O objetivo do trabalho é determinar uma equação para o coeficiente de flambagem local ( $\mathrm{k}_{\mathrm{l}}$ ) para aplicação do Método da Seção Efetiva (MSE) proposto pela norma brasileira. Os perfis são analisados para o esforço axial de compressão e para esforço de flexão simples. As análises foram realizadas no software GBTUL. Para o estudo paramétrico, foram desenvolvidos 95 perfis com diferentes variações geométricas. A partir das curvas de assinatura de cada análise obtém-se os respectivos valores de carga axial referente a flambagem local e momento fletor associado à flambagem local. Com uso das prescrições normativas brasileiras e dos resultados obtidos, foi possível determinar o valor de $\mathrm{k}_{1}$ para cada um dos perfis analisados. Assim, de acordo com o Método da Seção Efetiva apresentado pela norma, foram propostas duas equações para a determinação coeficiente de flambagem local $\left(\mathrm{k}_{1}\right)$, uma para a compressão centrada e outra para a flexão simples em torno do eixo de maior inércia. As equações mostraram-se adequadas para serem utilizadas no Método da Seção Efetiva para a tipologia de perfil apresentada, $\mathrm{U}$ enrijecido com mesa superior inclinada em $30^{\circ}$.
\end{abstract}

Palavras-chave: Perfil formado a frio; Perfil de chapa fina; Coeficiente de flambagem local; Método da seção efetiva.

\begin{abstract}
This work presents a study of cold-formed steel (CFS) profiles not standardized by standard, lipped channel section with top flange inclined at $30^{\circ}$. The goal is to determine an equation for the local buckling coefficient $\left(\mathrm{k}_{1}\right)$ to apply the Effective Section Method (ESM) proposed by the Brazilian standard. Profiles are analyzed for axial compressive stress and simple bending moment. Analyzes were performed using GBTUL software. For the parametric study, 95 profiles with different geometric variations were developed. From the signature curves of each analysis, the respective critical axial compressive load values for local buckling and critical bending moment associated with local buckling are obtained. Using the Brazilian normative prescriptions and the results obtained, it was possible to determine the value of $k_{1}$ for each of the analyzed profiles. Thus, according to the Effective Section Method presented by the standard, two equations were proposed to determine the local buckling coefficient $\left(\mathrm{k}_{1}\right)$, one for centered compression and one for bending moment around the axis of greatest inertia. The equations proved to be adequate to be used in the Effective Section Method for the type of profile presented, lipped channel section with flange inclined at $30^{\circ}$.

Keywords: Cold-formed steel member; Thin-walled profile; Local buckling coefficient; Effective section method.
\end{abstract}




\section{Resumen}

Este trabajo presenta un estudio de perfiles conformados en frío no estandarizados por estándar, con tipología U reforzado y mesa superior inclinada a $30^{\circ}$. El objetivo de este trabajo es determinar una ecuación para el coeficiente de pandeo local $\left(\mathrm{k}_{\mathrm{l}}\right)$ para aplicar el Método de Sección Efectiva (MSE) propuesto por la norma brasileña. Los perfiles se analizan para determinar el esfuerzo de compresión axial y el esfuerzo de flexión simple. Los análisis se realizaron utilizando el software GBTUL. Para el estudio paramétrico se desarrollaron 95 perfiles con diferentes variaciones geométricas. A partir de las curvas de firma de cada análisis, se obtienen los respectivos valores de carga axial para pandeo local y momento flector asociado con pandeo local. Utilizando las prescripciones normativas brasileñas y los resultados obtenidos, fue posible determinar el valor de $\mathrm{k}_{1}$ para cada uno de los perfiles analizados. Así, de acuerdo con el Método de Sección Efectiva presentado por la norma, se propusieron dos ecuaciones para determinar el coeficiente de pandeo local $\left(\mathrm{k}_{\mathrm{l}}\right)$, una para la compresión centrada y otra para la flexión simple alrededor del eje de mayor inercia. Las ecuaciones resultaron adecuadas para ser utilizadas en el Método de Sección Efectiva para el tipo de perfil presentado, $U$ reforzado con una mesa superior inclinada a $30^{\circ}$.

Palabras clave: Perfiles conformados en frío; Perfil de placa delgada; Coeficiente de pandeo local; Método de sección efectiva.

\section{Introdução}

Os Perfis de aço Formados a Frio (PFF), formados a partir da dobra de chapas finas de aço a temperatura ambiente, apresentam seções transversais variadas e possuem vasta aplicabilidade na construção civil, por serem leves e de fácil fabricação, transporte e montagem. Conforme Silva (2014), os PFF apresentam boa eficiência quando utilizados em casas populares, edifícios de pequeno porte, galpões de pequeno e médio porte, mezanino e coberturas. Por serem produzidos com chapas finas, são maleáveis, e por isso permitem seções transversais variadas, na Figura 1 é possível ver algumas das mais usuais. Porém, devido à espessura das chapas, possuem elevada esbeltez, o que pode ocasionar flambagem, instabilidade estrutural (Depolli, 2018).

Figura 1 - Seções transversais de PFF usuais, (a) perfil U; (b) perfil Ue; (c) perfil Z; (d) perfil Ze; (e) perfil cartola.

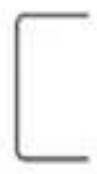

(a)

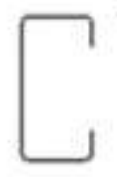

(b)

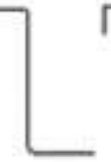

(c)

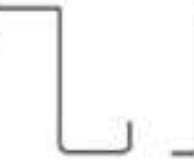

(d)

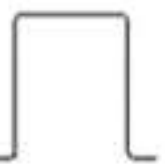

(e)

Fonte: Depolli (2018).

O perfil U é o mais aplicado em estruturas de aço com perfil formado a frio. Diversas variações são criadas para avaliar a melhoria e aplicabilidade dessa tipologia de perfil. Bruneau et al. (2014) apresentam diversas tipologias de perfis U com variações de enrijecedores intermediários (Figura 2) para melhorar a rigidez do perfil.

Figura 2 - Variações geométricas com enrijecedores de perfis U.
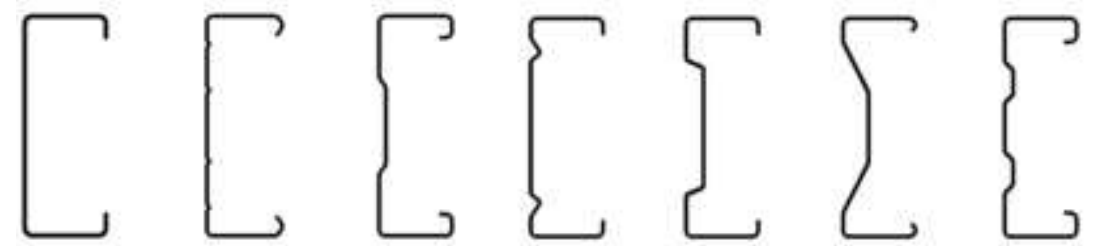

Fonte: Bruneau et al. (2014).

Para o dimensionamento dos perfis de aço formados a frio a ABNT NBR 14762 (2010) define as considerações no cálculo estrutural por meio de três métodos de cálculo: Método da Largura Efetiva (MLE), Método da Seção Efetiva (MSE) e 
Método da Rigidez Direta (MRD). O MSE é um método proposto por Batista (2010), no qual consiste na determinação de um coeficiente de flambagem local para a seção completa $\left(\mathrm{k}_{1}\right)$ e então determinação da respectiva carga de flambagem.

Visando a utilização em telhados e coberturas, neste trabalho é proposto uma tipologia de PFF em Ue com a mesa superior inclinada, representada na Figura 3. Como o perfil proposto não é padronizado por norma, tem-se por objetivo a definição e apresentação de uma formulação para a obtenção dos coeficientes de flambagem local da seção proposta, submetida a carregamento axial de compressão e à flexão simples. Assim, diversas configurações geométricas dos perfis foram simuladas no software GBTUL 2.06 (Bebiano et al. (2021)) para a determinação das respectivas cargas críticas de flambagem local e posterior determinação do coeficiente de flambagem local $\left(\mathrm{k}_{\mathrm{l}}\right)$.

Figura 3 - Tipologia de perfil proposta.

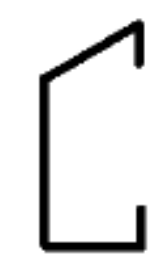

Fonte: Autores.

\section{Métodos de Cálculo}

Barras de seção transversal aberta, formadas por chapas finas de aço, apresentam modos de flambagem associados à flambagem local, distorcional ou global. A flambagem local é caracterizada pela formação de ondulações sem alterar a linha de união dos elementos, ocorre em um ou mais elementos do perfil. A distorcional mantém o ângulo entre as mesas e a alma, o modo se caracteriza pelo abaulamento da alma e rotação das mesas do perfil. E a global é caracterizada pela flexão da peça em seu eixo de maior ou menor inércia, ou por flexo torção. A partir da associação da flambagem local, distorcional e global é possível fazer o dimensionamento dos perfis formados a frio (ABNT NBR 14762, 2010). Exemplificações de possíveis modos de flambagem em um perfil Ue são apresentadas na Figura 4.

Figura 4 - Modos de flambagem de um perfil Ue: (a) local, (b) e (c) distorcional e (d) e (e) global.

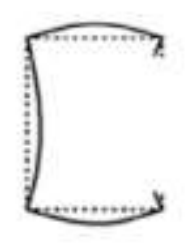

(a)

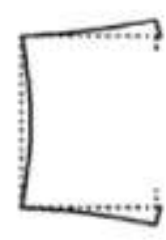

(b)

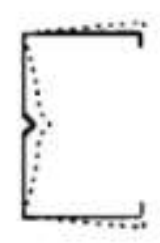

(c)

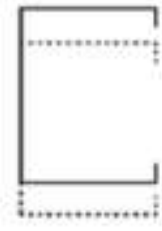

(d)

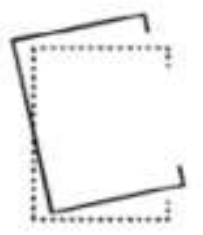

(e)

Fonte: Paixão (2018)

\subsection{Resistência pós flambagem}

Segundo Schafer (1997), as tensões críticas de flambagem são inferiores à tensão de escoamento do material em perfis com alta esbeltez. Os elementos dos PFF por serem esbeltos possuem esse comportamento, um pouco diferente, se comparadas às colunas comprimidas. Ao contrário das colunas estruturais unidimensionais, os elementos de compressão enrijecidos não entram em colapso quando atingem a tensão de flambagem. A distribuição de tensão inicialmente é uniforme antes de sua flambagem, após a flambagem, uma parcela da carga de pré-flambagem da região central é transferida para a borda da placa. Como resultado, uma distribuição de tensão não uniforme é desenvolvida. A redistribuição da tensão continua até que a tensão 
na borda alcance a tensão de escoamento do aço e então a placa começa a falhar. Assim, é então caracterizado o fenômeno de resistência pós-flambagem (Yu \& LaBoube, 1924). Esse fenômeno pode ser dividido em três fases, demonstradas na Figura 5, onde (a) descreve a distribuição uniforme de tensões, (b) descreve o estado após atingir a tensão crítica, onde há uma redistribuição de tensões, e a tensão da borda é maior, mas ainda não atingiu o escoamento e (c) descreve a fase em que a tensão na borda atinge a tensão de escoamento, resultando no colapso (Carvalho et al., 2018).

Figura 5 - Redistribuição da carga no momento da flambagem local.
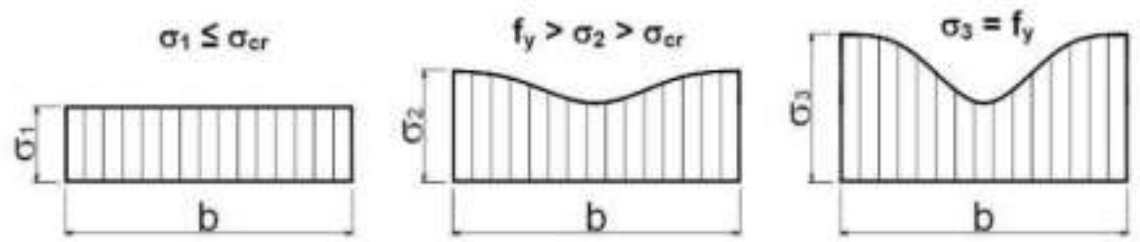

Fonte: Adaptado de Carvalho et al. (2018).

\subsection{Carga de flambagem}

Segundo Ziemian (2010) a força crítica de flambagem é a força que gera a mudança do estado de equilíbrio, ou seja, é a carga máxima que o elemento estrutural pode suportar e com qualquer carga adicional ocorre o fenômeno de flambagem. Conforme já apresentado, os PFF podem desenvolver três tipos de flambagem: local, distorcional e global. A correta identificação dos modos de flambagem e cargas críticas está ligada ao projeto e ao cálculo da resistência dos PFF e conforme Nunes (2016), as dimensões e a variação geométrica de uma seção têm relação direta com o comportamento de flambagem.

A Teoria da Viga Generalizada (GBT), desenvolvida inicialmente por Schardt (1994) e seguido por Davies et al. (1994), é uma ferramenta eficiente para as análises de flambagem, sendo possível, por meio dela, realizar a decomposição modal. O programa computacional GBTUL (Bebiano et al., 2021) disponível gratuitamente, baseado na Teoria da Viga Generalizada (GBT) permite a identificação dos modos de flambagem e das cargas críticas associadas aos modos de flambagem. Outros métodos para determinação da carga crítica de flambagem e assim definição da curva de assinatura também podem ser usados, como método dos elementos finitos, método das faixas finitas, entre outros apresentados na literatura ((Lazzari \& Batista, 2021), (Campos et al., 2019), (Gustavo Y. Matsubara et al., 2019)).

Conforme Matsubara (2018), a curva de assinatura trata-se de uma representação gráfica das cargas críticas para colunas e vigas, descrevendo o perfil com a variação de seu comprimento. É possível obter essa curva com uso de softwares, como o GBTUL (BEBIANO et al., 2010), que é baseado na teoria generalizada de vigas. A curva é muito importante, uma vez que é utilizada para projetar colunas e vigas, pois possibilita que seja previsto o modo em que será perdida a estabilidade das peças.

Na Figura 6 é apresentado a curva de assinatura de um perfil qualquer, como exemplo a ser analisado. O perfil possui módulo de elasticidade $(E)=200000 \mathrm{MPa}$ e coeficiente de Poisson $(v)=0,3$. Cada um dos mínimos da curva é uma carga crítica do modo de flambagem relacionado. 
Figura 6 - Curva de assinatura de um perfil U enrijecido.

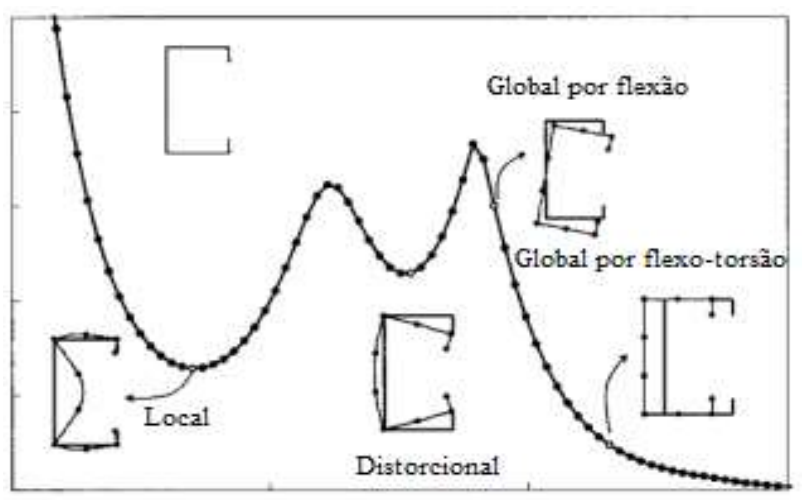

Fonte: Adaptado de Garcia (2015).

A curva demonstra que a flambagem local possui valor mínimo e, conforme o comprimento aumenta, esse valor oscila, porém não há alteração da carga crítica. O mesmo pode ser percebido para a flambagem distorcional, onde há uma oscilação da carga, mas sem alteração da carga crítica. Para comprimentos elevados, de acordo com a tipologia de perfil, temse o domínio da flambagem global. A partir da curva de assinatura é possível fazer o dimensionamento com uso do Método da Resistência Direta apresentado na ABNT NBR 14762 (2010).

\subsection{Método da Resistência Direta}

O MRD foi desenvolvido por Schafer e Peköz (1998), com o intuito de melhorar a eficiência dos PFF, e ele requer a determinação das cargas críticas dos perfis, sendo elas flambagem local, distorcional e global, cargas essas que são determinadas a partir de métodos computacionais, por meio das propriedades da seção bruta dos perfis, através de análises numéricas ou analíticas. A resistência $\left(\mathrm{P}_{\mathrm{r}}\right)$ é dada pelo menor valor entre aqueles determinados para os modos global, distorcional e local, respectivamente, $\mathrm{P}_{\mathrm{Ne}}, \mathrm{P}_{\mathrm{Nd}}$ e $\mathrm{P}_{\mathrm{Nl}}$ (que inclui interação de flambagem local-global) conforme o Anexo $\mathrm{C}$ da ABNT NBR 14762 (2010).

Outros dois métodos de dimensionamento alternativos podem ser utilizados, sendo eles o Método da Largura Efetiva e o Método da Seção Efetiva são apresentados pela ABNT NBR 14762 (2010).

\subsection{Método da Largura Efetiva}

O Método da Largura Efetiva (MLE), proposto por Von Kárman, considera que a flambagem local é obtida por meio das propriedades geométricas reduzidas do perfil, calculando as larguras efetivas dos elementos comprimidos. Essa largura efetiva desconsidera o trecho já flambado da seção analisada. O MLE é um método clássico, bastante empregado mundialmente e descrito em diversas bibliografias como Yu e LaBoube (1924) e prescrições normativas (ABNT NBR 14762, 2010; AISI, 2003). Porém, trata-se de um cálculo algumas vezes complexo, uma vez que muitas vezes são necessários processos iterativos, dificultando o uso na prática. Alternativamente a ABNT NBR 14762 (2010) apresenta o Método da Seção Efetiva.

\subsection{Método da Seção Efetiva}

Segundo a ABNT NBR 14762 (2010), o Método da Seção Efetiva (MSE) permite a determinação da carga axial de compressão de flambagem local, assim como o momento fletor que provoca flambagem local de um perfil de aço, utilizando as propriedades geométricas efetivas da seção transversal da barra. O MSE possui os mesmos princípios do MRD, sendo uma derivação dele, e permite um cálculo direto, uma vez que os esforços resistentes da barra não são mais calculados 
separadamente em cada elemento, como no MLE, mas sim considerando a iteração de todos os elementos da seção. Esse é um método utilizado apenas no Brasil, e foi inserido na norma brasileira após ensaios experimentais das curvas de resistência.

Baseado em estudos paramétricos Batista (2010) definiu curvas que permitem a determinação do coeficiente de flambagem local $\left(\mathrm{k}_{\mathrm{l}}\right)$ para diversos tipos de seção, conforme apresentado na Figura 7. A partir desse estudo a ABNT NBR 14762 (2010) apresenta equações de $\mathrm{k}_{1}$ para algumas tipologias de perfis (Tabela 1). Assim, o método consiste na determinação do coeficiente de flambagem local $\left(\mathrm{k}_{1}\right)$ e posterior cálculo da carga que provoca flambagem local, seja para compressão e/ou momento fletor.

Figura 7 - Curvas do coeficiente de flambagem local para diferentes perfis.

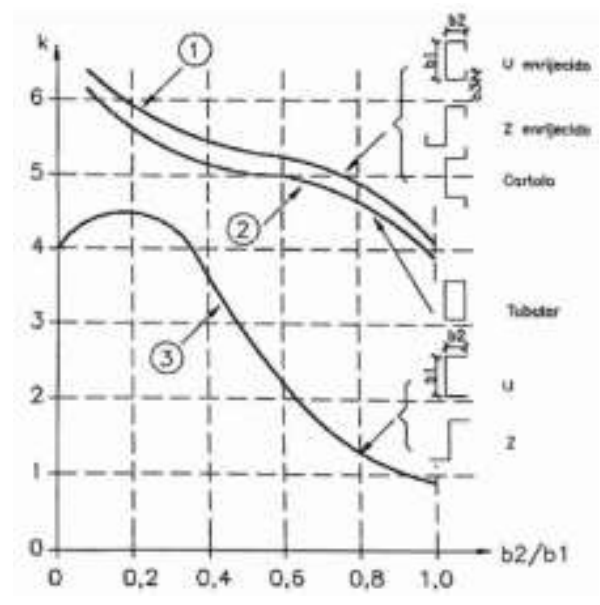

Fonte: Batista (2010)

Tabela 1 - Coeficiente de flambagem local $\left(\mathrm{k}_{\mathrm{l}}\right)$ conforme ABNT NBR 14762 (2010).

\begin{tabular}{ll}
\hline & Barras sob compressão centrada \\
\hline Seção U simples e Z simples & $\mathrm{k}_{1}=4+3,4 \eta+21,8 \eta^{2}-174,3 \eta^{3}+319,9 \eta^{4}-237,6 \eta^{5}+63,6 \eta^{6}$ \\
Seção U enrijecido, Z enrijecido e Cartola & $\mathrm{k}_{1}=6,8-5,8 \eta+9,2 \eta^{2}-6,0 \eta^{3}$ \\
Seção Rack & $\mathrm{k}_{1}=6,5-3,0 \eta+2,8 \eta^{2}-1,6 \eta^{3}$ \\
Seção tubular retangular & $\mathrm{k}_{1}=6,6-5,8 \eta+8,6 \eta^{2}-5,4 \eta^{3}$ \\
\hline \multicolumn{2}{c}{ Barras sob flexão simples em torno do eixo de maior inércia } \\
\hline Seção U simples e Z simples & $\mathrm{k}_{1}=\eta^{-1,843}$ \\
Seção U enrijecido, Z enrijecido e Cartola & $\mathrm{k}_{1}=a-b(\mu-0,2)$ \\
& $a=81-730 \eta+4261 \eta^{2}-12304 \eta^{3}+17919 \eta^{4}-12796 \eta^{5}+3574 \eta^{6}$ \\
& $b=320-2788 \eta+13458 \eta^{2}-27667 \eta^{3}+19167 \eta^{4}$ \\
Seção tubular retangular & $\mathrm{k}_{1}=14,5+178 \eta-602 \eta^{2}+649 \eta^{3}-234 \eta^{4}$ \\
\hline$\eta=\mathrm{b}_{\mathrm{f}} / \mathrm{b}_{\mathrm{w}}$ & \\
$\mu=\mathrm{D} / \mathrm{b}_{\mathrm{w}}$ & \\
\hline
\end{tabular}

Fonte: Autores.

\section{Metodologia}

Nesse trabalho foi realizado um estudo teórico e numérico de um perfil Ue formado a frio para aplicação em terças de coberturas de telhados. O perfil proposto ainda não foi investigado em estudos científico, tratando-se de um estudo de caso no qual avalia-se a aplicabilidade desse perfil. Para isso, uma avaliação quantitativa foi desenvolvida e analisou-se a influência de parâmetros geométricos do perfil Ue nas cargas críticas de flambagem local associadas a compressão centrada e a momento fletor no eixo de maior inércia.

Assim, para o desenvolvimento desse trabalho 95 perfis Ue, com mesa inclinada foram analisados por meio do software GBTUL 2.06 (Bebiano et al, 2010), submetidos à compressão axial e à flexão simples. Para a definição do estudo 
paramétrico as geometrias foram definidas por meio de adaptações de configurações geométricas apresentadas na prescrição normativa ABNT NBR 6355 (2003).

\subsection{Geometria e descrição da análise}

Os perfis estudados apresentam mesa superior inclinada a $30^{\circ}$, altura de alma $\left(b_{w}\right)$ variando entre $50 \mathrm{~mm}$ a $300 \mathrm{~mm}$, mesa inferior $\left(b_{f}\right)$ variando de $20 \mathrm{~mm}$ a $100 \mathrm{~mm}$, espessura $(\mathrm{t})$ variando entre $1,20 \mathrm{~mm}$ a 6,30 mm e enrijecedores (D) variando de $10 \mathrm{~mm}$ a $25 \mathrm{~mm}$. Na Figura 8 é apresentado o modelo geométrico do perfil adotado.

Figura 8 - Seção transversal genérica do perfil analisado.

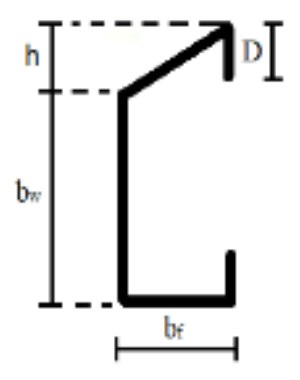

Fonte: Autores.

Para analisar esses perfis, foram criados, no GBTUL, nós intermediários com o intuito de obter resultados mais refinados. Nas mesas do perfil, foram criados nós intermediários a cada $5 \mathrm{~mm}$, e na alma, nós intermediários a cada $10 \mathrm{~mm}$. Além disso, foram utilizadas as seguintes propriedades mecânicas do aço para a obtenção dos resultados: módulo de elasticidade (E) igual a $200000 \mathrm{MPa}$; módulo de elasticidade transversal (G) igual a $77 \mathrm{GPa}$; coeficiente de Poisson (v) igual a 0,3 ; e resistência ao escoamento $\left(\mathrm{f}_{\mathrm{y}}\right)$ igual a $250 \mathrm{MPa}$.

Inicialmente os modelos foram simulados considerando aplicação de carga axial de compressão. Após essa análise os modelos foram submetidos a momento fletor. A curva de assinatura gerada no software GBTUL permite a definição da carga axial de compressão associada à flambagem local $\left(\mathrm{N}_{\mathrm{l}}\right)$ e o momento fletor de flambagem local $\left(\mathrm{M}_{\mathrm{l}}\right)$.

Desse modo, com os resultados obtidos de cada perfil, calcula-se o coeficiente de flambagem local para a seção completa $\left(\mathrm{k}_{\mathrm{l}}\right)$, por meio da Eq. (1) (para perfis sob compressão centrada) e da Eq. (2) (para perfis sob flexão simples em torno do eixo de maior inércia), derivadas da ABNT NBR 14762 (2010).

$$
\begin{aligned}
& \mathrm{k}_{1, \mathrm{c}}=\frac{\mathrm{N}_{1}}{\frac{\pi^{2} \cdot \mathrm{E}}{12\left(1-v^{2}\right)\left(\frac{\mathrm{b}_{\mathrm{w}}}{\mathrm{t}}\right)^{2}} \times \mathrm{A}} \\
& \mathrm{k}_{\mathrm{l}, \mathrm{f}}=\frac{\mathrm{M}_{\mathrm{l}}}{\frac{\pi^{2} \cdot \mathrm{E}}{12\left(1-\mathrm{v}^{2}\right)\left(\frac{\mathrm{b}_{\mathrm{w}}}{\mathrm{t}}\right)^{2}} \times \mathrm{W}_{\mathrm{c}}}
\end{aligned}
$$

Onde:

$\mathrm{k}_{\mathrm{l}, \mathrm{c}}$ é o coeficiente de flambagem local para barras sob compressão centrada;

$\mathrm{k}_{\mathrm{l}, \mathrm{f}}$ é o coeficiente de flambagem local para barras sob flexão simples em torno do eixo de maior inércia;

E é módulo de elasticidade;

$v$ é o Coeficiente de Poisson; 
$\mathrm{b}_{\mathrm{w}}$ é largura nominal da alma;

t é espessura do elemento;

A é a área bruta da seção transversal da barra

$\mathrm{W}_{\mathrm{c}}$ é o módulo de resistência elástico da seção bruta em relação à fibra comprimida;

$\mathrm{N}_{1}$ é a força axial de flambagem local elástica;

$\mathrm{M}_{1}$ é o momento fletor de flambagem local elástica.

\section{Resultados e Discussão}

Com os valores obtidos pelo software GBTUL para $\mathrm{N}_{1}$ e $\mathrm{M}_{\mathrm{l}}$, e utilizando Eq. (1) e Eq. (2), encontrou-se os valores referentes a $\mathrm{k}_{1}$ para cada perfil.

Os resultados são apresentados na Figura 9(a) para a compressão axial e na Figura 9(b) para flexão simples. Os coeficientes de flambagem local $\left(\mathrm{k}_{\mathrm{l}}\right)$ propostos são apresentados na Tabela 2 por Eq. (3) e Eq. (4), respectivamente para compressão centrada e flexão simples em torno do eixo de maior inércia, obtidas por regressão polinomial das curvas das Figura 9. Assim, é possível obter o valor do coeficiente de flambagem local $\left(k_{1}\right)$ em função de $\eta$ e a aplicação do MSE.

Tabela 2 - Coeficiente de flambagem local k proposto para a seção completa.

\begin{tabular}{l}
$\begin{array}{l}\text { Barra sob compressão centrada } \\
\quad \mathrm{k}_{1}=7,6347-5,3696 \eta-93,839 \eta^{2}+679,08 \eta^{3}-1883,4 \eta^{4}+2396,3 \eta^{5}-1164,5 \eta^{6}\end{array}$ \\
\hline $\begin{array}{l}\text { Barra sob flexão simples em torno do eixo de maior inércia } \\
\quad \mathrm{k}_{1}=-1276,2+18509 \eta-105239 \eta^{2}+311754 \eta^{3}-513225+447141 \eta^{5}-161357 \eta^{6}\end{array}$ \\
\hline Notas: \\
$\eta=\mathrm{b}_{\mathrm{f}} / \mathrm{b}_{\mathrm{w}}$ \\
$\mathrm{b}_{\mathrm{f}}, \mathrm{b}_{\mathrm{w}}, \mathrm{D}$ são as dimensões nominais dos elementos, conforme indicado na Figura 8 \\
Formulações válidas para $(0,1 \leq \eta \leq 1,0)$ e $\left(0,1 \leq \mathrm{D} / \mathrm{b}_{\mathrm{w}} \leq 0,3\right)$ \\
Fonte: Autores.
\end{tabular}

Figura 9 - Curva da equação de $\mathrm{k}_{1}$ para o perfil estudado.

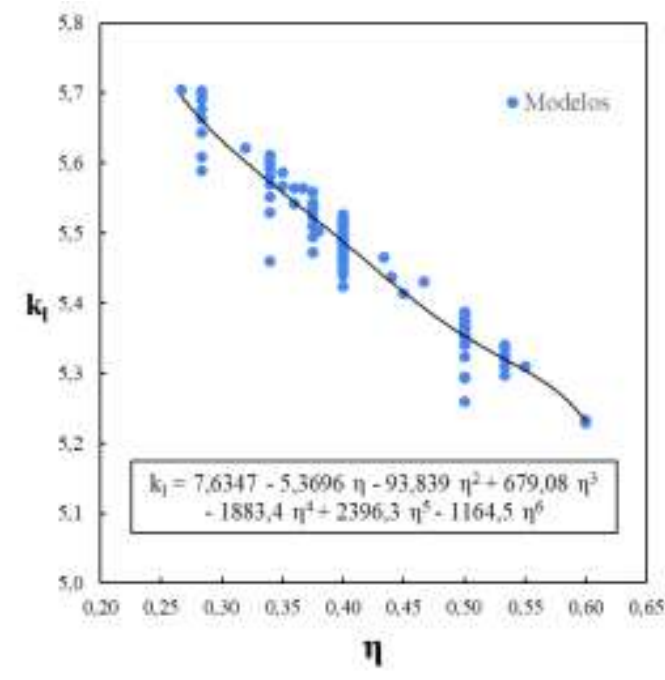

(a) sob à força axial de compressão

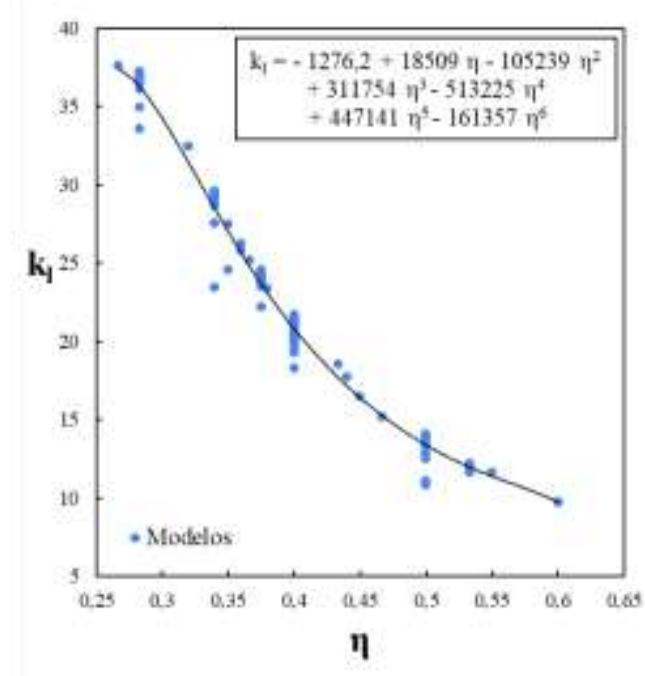

(b) sob flexão simples em torno do eixo de maior inércia

Fonte: Autores.

Os resultados dos coeficientes de flambagem local, calculados por meio das formulações propostas ( $\mathrm{k}_{1, p r o p}$ ), Eq. (3) e Eq. (4), foram comparados com os valores obtidos por meio da análise numérica pelo GBTUL ( $\mathrm{k}_{1, \text { num }}$ ), conforme apresentado 
na Figura 10. A relação entre os resultados numéricos e os resultados obtidos pela formulação proposta ( $\left.\mathrm{k}_{1, \text { num }} / \mathrm{k}_{1, \text { prop }}\right)$ devem se aproximar da linha tangente $45^{\circ}$, que indica que a relação $\mathrm{k}_{1, \text { num }} / \mathrm{k}_{1, \text { prop }}$ é igual a 1,00 . Na Figura 10 observa-se boa correlação entre a formulação proposta e os resultados numéricos. Na Figura 10(a), para os perfis submetidos a compressão centrada, a relação $\mathrm{k}_{1, \text { num }} / \mathrm{k}_{1, \text { prop }}$ é igual, em média, a 1,0001, com coeficiente de variação (CoV) igual a 0,0055. E para os perfis submetidos flexão simples em torno do eixo de maior inércia, a relação $\mathrm{k}_{1, \text { num }} / \mathrm{k}_{\mathrm{l} \text {,prop }}$ é igual, em média, a 1,0090, com CoV = 0,0473 (Figura 10(b)). Assim, as equações propostas são adequadas para determinação do coeficiente de flambagem local para o perfil Ue com mesa inclinada a 30 e aplicação do Método da Seção Efetiva (MSE) apresentado pela ABNT NBR 14762 (2010).

Figura 10 - Comparação entre valores numéricos e valores obtidos pela equação proposta.

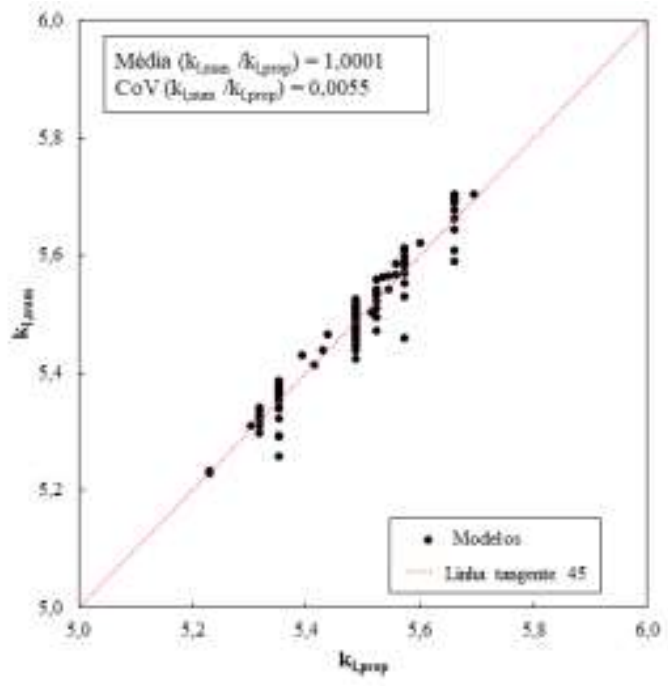

(a) perfil submetido à compressão centrada

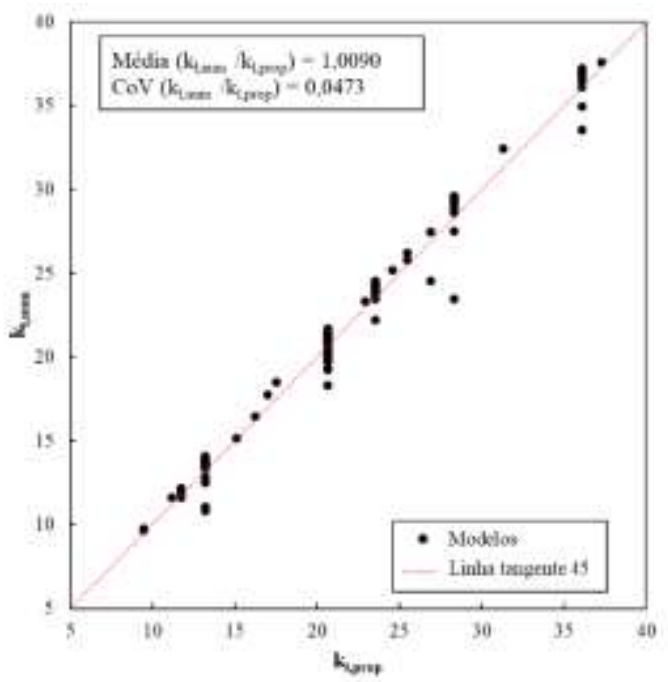

(b) perfil submetido à flexão simples

Fonte: Autores.

\section{Considerações Finais}

Neste trabalho foi apresentado um estudo para proposição de duas formulações para a obtenção do coeficiente de flambagem local $\left(\mathrm{k}_{\mathrm{l}}\right)$ para seção completa de um perfil de chapa fina (perfil formado a frio). O perfil estudado foi do tipo Ue, com mesa superior inclinada a $30^{\circ}$.

A análise numérica foi realizada por meio do software GBTUL 2.06. Foram simulados 95 perfis com diferentes variações geométricas. O perfil foi avaliado sob à compressão centrada e, separadamente, sob flexão simples em torno do eixo de maior inércia. A partir dos resultados obtidos para a força axial de flambagem local elástica $\left(\mathrm{N}_{1}\right)$ e para o momento fletor de flambagem local elástica $\left(\mathrm{M}_{1}\right)$ foi possível determinar os respectivos valores do coeficiente de flambagem local ( $\left.\mathrm{k}_{\mathrm{l}}\right)$ para cada perfil. Com os valores de $\mathrm{k}_{1}$ foi possível propor duas equações para determinação direta do $\mathrm{k}_{1}$ sem uso de análise de instabilidade.

Os resultados dos coeficientes de flambagem local $\left(\mathrm{k}_{1}\right)$ obtidos pelas equações propostas indicaram boa correlação com os resultados numéricos obtidos pelo GBTUL. Assim, as equações propostas são adequadas para determinação do coeficiente de flambagem local para o perfil Ue com mesa inclinada a 30. Consequentemente, é possível a aplicação do Método da Seção Efetiva (MSE) conforme apresentado pela norma brasileira ABNT NBR 14762 (2010), obtendo-se diretamente os valores para a força axial de flambagem local elástica $\left(\mathrm{N}_{\mathrm{l}}\right)$ e para o momento fletor de flambagem local elástica $\left(\mathrm{M}_{1}\right)$. O que permite a determinação dos valores de resistência do perfil de maneira mais rápida e prática. 
Como trabalhos futuros é possível a realização de uma comparação dos resultados obtidos pela análise do GBTUL (Teoria de Viga Generalizada) com os resultados obtido por meio de uma análise em elementos finitos. Além disso, uma proposta de aplicação da utilização do perfil em uma situação real, como por exemplo, o dimensionamento do perfil proposto aplicado como terça de um telhado.

\section{Agradecimentos}

Os autores agradecem a Capes, UFSJ e UFOP.

\section{Referências}

ABNT NBR 14762. (2010). Dimensionamento de Estruturas de Aço constituídas por Perfis Formados a Frio (Associação Brasileira de Normas Técnicas (ed.)).

ABNT NBR 6355. (2003). Perfis estruturais de aço formados a frio - Padronização.

AISI. (2003). American Iron and Steel Institute, AISI Manual Cold-Formed Steel Design 2002 Edition (2002 Editi). AISI-Specifications for the Design of Cold-Formed Steel Structural Members.

Batista, E. de M. (2010). Effective section method: A general direct method for the design of steel cold-formed members under local-global buckling interaction. Thin-Walled Structures, 48(4-5), 345-356. https://doi.org/10.1016/j.tws.2009.11.003

Bebiano, R., Silvestre, N., \& Camotim, D. (2021). Generalised Beam Theory Research Group at Lisbon (P. Instituto Superior Técnico, University of Lisbon (ed.)).

Bruneau, L. A., Pham, C. H., \& Hancock, G. J. (2014). Experimental study of longitudinally stiffened web channels subjected predominantly to shear. 22nd International Specialty Conference on Recent Research and Developments in Cold-Formed Steel Design and Construction, 329-343.

Campos, A. I. de, Batista, E. de M., \& Franco, J. M. S. (2019). Stability And Strength Of Cold-Formed Steel Columns With Intermediate Stiffeners. Proceedings of the XL Ibero-Latin-American Congress on Computational Methods in Engineering, ABMEC.

Carvalho, P. R. M. de, Grigoletti, G., \& Barbosa, G. D. (2018). Curso básico de perfis de aço formados a frio (3ed.).

Davies, J. M., Leach, P., \& Heinz, D. (1994). Second-order generalised beam theory. Journal of Constructional Steel Research, 31(2-3), 221-241. https://doi.org/10.1016/0143-974X(94)90011-6

Depolli, I. C. (2018). Dimensionamento à falha distorcional via método da resistência direta de vigas de aço em perfil formado a frio sob flexão nãouniforme. Universidade Federal do Rio de Janeiro.

Garcia, R. A. S. (2015). Behaviour and DSM desing of cold-formed steel web/flange stiffened lipped channel columns experiencing distortional failure. COOPE UFRJ, Instituto Alberto Luiz Coimbra de Pós-Graduação e Pesquisa de Engenharia, Rio de Janeiro.

Lazzari, J. A. de, \& Batista, E. de M. (2021). Finite strip method computer application for buckling analysis of thin-walled structures with arbitrary crosssections. REM - International Engineering Journal, 74(3), 337-344. https://doi.org/10.1590/0370-44672020740065

Matsubara, Gustavo Y., Batista, E. de M., \& Salles, G. C. (2019). Lipped channel cold-formed steel columns under local-distortional buckling mode interaction. Thin-Walled Structures, 137, 251-270. https://doi.org/10.1016/j.tws.2018.12.041

Matsubara, Gustavo Yoshio. (2018). Análise da interação entre modos de flambagem local e distorcional em perfil de aço formados a frio com seção U enrijecido sob compressão axial. Universidade Federal do Rio de Janeiro.

Nunes, R. D. (2016). Sobre o dimensionamento via MRD de colunas de aço em PFF com seção Ue sob modo de falha distorcional e temperaturas elevadas. COPPE/UFRJ.

Paixão, J. F. M. (2018). Dimensionamento via método da resistência direta de colunas em aço inoxidável de parede fina sob falha distorcional. Universidade Federal do Rio de Janeiro.

Schafer, B. W. (1997). Cold-formed steel behavior and design: analytical and numerical modeling of elements and members with longitudinal stiffeners. Cornell University, Ithaca, New York.

Schafer, B. W., \& Peköz, T. (1998). Direct strength prediction of cold-formed steel members using numerical elastic buckling solutions. Fourteenth International Specialty Conference on Cold-Formed Steel Structures.

Schardt, R. (1994). Generalized beam theory — an adequate method for coupled stability problems. Thin-Walled Structures, 19, 161-180.

Silva, E. L. (2014). Estruturas compostas por perfis formados a frio-Dimensionamento pelo método das larguras efetivas e aplicação conforme ABNT NBR 14762:2010 e ABNT NBR6355:2012 (Série Manual de Construção em Aço (ed.).

Yu, W., \& LaBoube, R. A. (1924). Cold-formed steel design (4th ed.).

Ziemian, R. D. (2010). Guide to stability design criteria for metal structures (John Wiley \& Sons (ed.). 